\title{
Diagnosi de l'oferta educativa per al batxillerat relacionada amb el medi litoral en centres d'educació ambiental
}

\author{
Concepció Rodon Galceran \\ SES Teià \\ cupirodon@gmail.com
}

Els resultats de la recerca realitzada descriuen les característiques dels centres d'educació ambiental que treballen el medi litoral-marí a Catalunya i de l'oferta d'activitats destinades a batxillerat. Treballar les ciències in situ des de centres que ja formulen activitats d'entorn fa que l'aprenentatge sigui més rellevant, reflexiu, participatiu i dinàmic.

Paraules clau: educació ambiental, batxillerat, medi litoral-marí, recursos

\section{INTRODUCCIÓ}

La matèria de les Ciències de la Terra i del medi ambient és una finestra oberta per treballar més aviat des d'un punt de vista d'aplicació i també d'acció sobre l'entorn.

L'enfocament interdisciplinari de la matèria i la necessitat social de replantejar les relacions entre l'ésser humà i el seu medi ofereixen un gran ventall de possibilitats per estudiar ecosistemes concrets. L'ecosistema marí serà el nostre fil conductor per al coneixement de l'entorn a través dels centres d'educació ambiental que ja formulen activitats concretes sobre aquest medi.

Les activitats d'aquests centres d'educació ambiental són molt diverses; però en general apropen l'alumnat al medi, li proposen un treball participatiu i dinàmic que el motiva i l'ajuden a ser més receptiu en diferents aspectes del que l'envolta, el conviden a la reflexió i a l'acció per millorar l'entorn. A més a més, les visites guiades en alguns centres permeten accedir a espais d'interès científic que fan la sortida encara més singular. A partir d'aquestes consideracions aprofundim en la relació entre l'ensenyament a les aules ordinàries $i$ els fenòmens que podem observar, mesurar, relacionar, qüestionar, gestionar... fora de les aules, amb l'oferta dels centres d'educació ambiental per apropar als joves a l'observació i l'experimentació en el medi litoralmarí.

\section{Sobre l'educació ambiental}

El concepte d'educació ambiental (a partir d'ara EA) s'ha anat modelant al llarg dels anys i actualment es debat una tendència a utilitzar el terme d'Educació per al Desenvolupament Sostenible o Educació per la Sostenibilitat per substituir el terme d'EA.

El plantejament més clàssic de la història de l'EA estableix tres enfocaments: l'educació sobre el medi, a través del medi i per al medi (Lucas,1979).

L'educació en el medi reconeix que els comportaments estan guiats molt més per les nostres emocions i valors que no pas pels coneixements $i$ que, per tant, és necessari no només oferir informacions sinó també proposar experiències que reconstrueixin les connexions entre els humans i el medi (Mayer,1998). La integració dels tres enfocaments ens permetrà moure'ns cap a un model holístic i més real (Tilbury, 1995).

L'EA es pot desenvolupar des de diferents àmbits: l'àmbit formal, el no formal i l'informal. Tots tres àmbits són complementaris i configuren una important oferta de formació (Novo, 1995):

- L'EA formal es realitza a través de plans d'estudis o programes educatius en un marc institucional creat amb finalitat educativa i dins de l'educació reglada. 
- L'EA no formal es realitza fora de l'educació reglada i els programes educatius són desenvolupats per entitats diverses que ofereixen activitats a estudiants i públic en general. Els processos d'aprenentatge són més dinàmics i motivadors i s'organitzen en centres d'EA.

- L'EA informal es realitza des dels mitjans de comunicació, sense un programa educatiu però sí amb potencial educatiu, sobretot com a font de material. Una prova de la importància d'aquest àmbit és la recent presentació de l'Edu3.cat, una iniciativa pionera a l'estat espanyol que reuneix en un sol portal un ampli ventall de materials audiovisuals educatius produïts per Televisió de Catalunya, Catalunya Ràdio i el Departament d'Educació.

Els sectors de l'educació no formal i de l'educació informal tenen el mateix grau de responsabilitat i els tres àmbits han de treballar junts per aconseguir les finalitats de la sostenibilitat (McKeown, 2002).

\section{METODOLOGIA DE LA RECERCA}

Per descriure l'oferta educativa relacionada amb el medi litoral-marí català en els centres d'EA per a alumnat de batxillerat en l'àmbit de les ciències de la naturalesa es realitza l'estudi durant el curs 2007-2008 amb un disseny comparatiu causal i una metodologia quantitativa, aplicada i descriptiva.

L'univers de l'estudi consta de 43 centres d'EA que treballen el medi litoral marí en les comarques litorals catalanes. Se'n seleccionen els 22 centres que ofereixen un total de 35 activitats per a batxillerat (fig. 1).

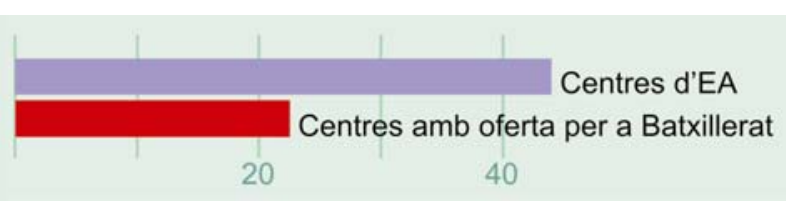

Figura 1. Centres del medi litoral-marí en comparació amb els que ofereixen activitats per a batxillerat.

Els centres d'EA són molt variats: escoles del mar, centres d'estudis del mar, camps d'aprenentatge, centres d'informació i d'interpretació, museus, centres d'immersió, centres d'investigació del mar i fundacions. No s'hi han considerat els grups de protecció del medi ni els grups ecologistes que ofereixen activitats destinades a tot el públic i fora de l'horari lectiu. Es desestimen també les empreses que confeccionen materials per altres centres i els ens públics, ja que es considera que queden inclosos en el centre d'EA on es treballen aquests materials.

Les variables que s'han estudiat s'agrupen en dos blocs: un primer bloc sobre diferents aspectes del centre i un segon bloc sobre diferents aspectes de l'activitat que s'hi realitza.

Els instruments de recollida de dades són l'anàlisi de fons documentals, els qüestionaris sobre les dades d'ubicació del centre d'EA, sobre les diferents activitats per a batxillerat i sobre la dinàmica del centre i en l'observació directa de les activitats.

Un cop realitzada una prova pilot en cinc centres es procedeix al treball de camp per a la recollida de dades i la seu posterior anàlisi.

\section{RESULTATS}

\section{Sobre els centres d'educació ambiental}

Les dades recollides en els inventaris realitzats en anys diferents permeten d'establir una evolució creixent del nombre de centres d'EA i de la seva tipologia (fig. 2)

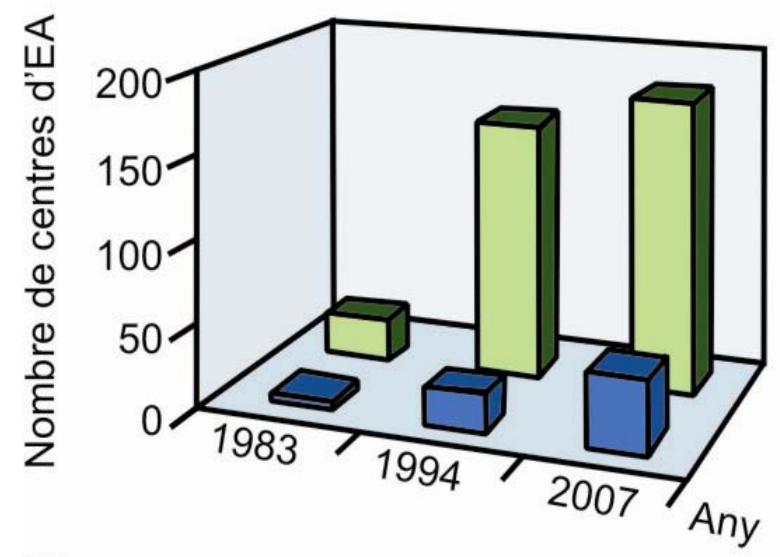

Centres d'EA del medi litoral-marí

\section{Total de centres d'EA}

Figura 2. Evolució del nombre de centres d'EA en els darrers anys.

Dels centres d'EA que treballen el medi litoral marí només la meitat ofereixen activitats per a batxillerat. Predominen els centres que són de titularitat pública. Concretament n'hi ha dels ajuntaments, 
de les diputacions, de la Generalitat i de consorcis que agrupen ens diversos. La resta de centres són privats, com fundacions, associacions i particulars (fig. 3).

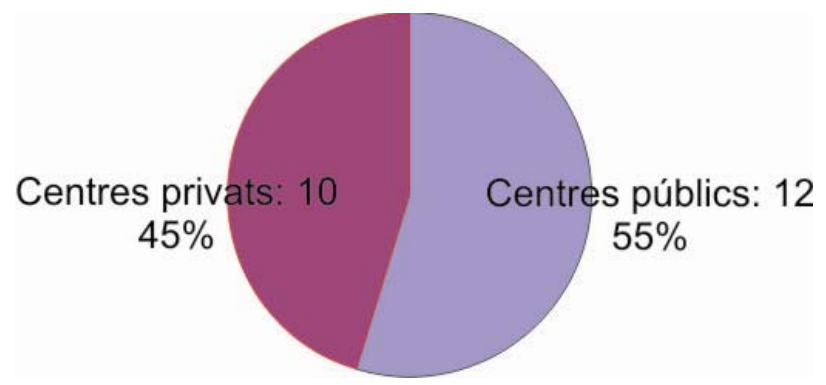

Figura 3. Propietat dels centres.

Els centres d'EA estudiats es distribueixen en totes les comarques $\mathrm{i}$ es concentren en les àrees més poblades de l'àrea metropolitana de Barcelona i de Tarragona. Majoritàriament els centres es troben i tenen el seu marc d'actuació fora dels espais del PEIN, Pla d'Espais d'Interès Natural. Cal dir que les zones costaneres incloses en aquesta categorització són poques i que les zones més densament poblades es situen justament en la franja costanera (fig. 4).

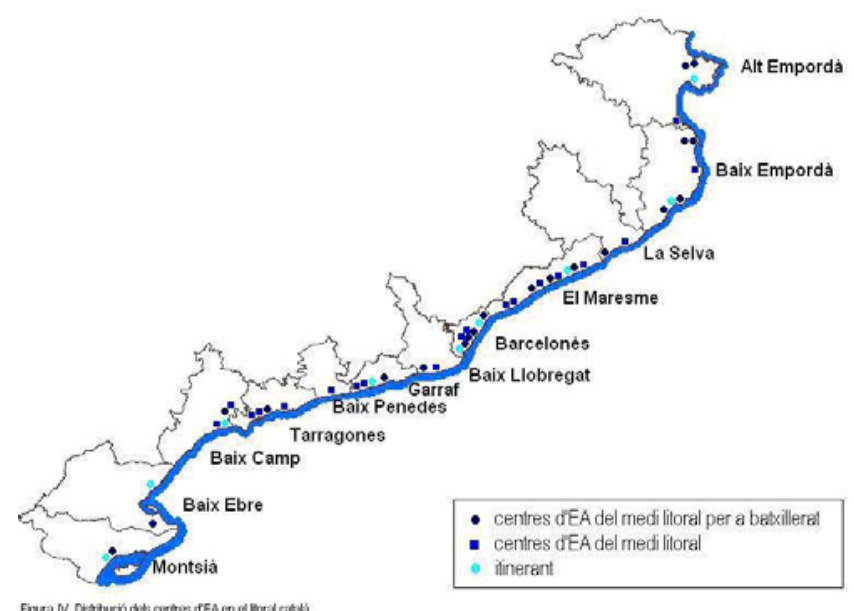

Figura 4. Distribució de centres d'EA en el litoral català.

Més de la meitat dels centres d'EA seleccionats en la recerca no es troben recollits en el Cens General d'Entitats d'EA de la Generalitat de Catalunya: la majoria de centres públics no hi estan inscrits. Entitats recopilades en altres inventaris amb una trajectòria històrica molt potent no estan recollits en el Cens, fent-lo poc fiable com a inventari real i permanent de les entitats d'EA, segurament atribuïble a la inscripció voluntària al Cens. Per altra banda, la inscripció a aquest Cens és condició necessària perquè una entitat rebi una subvenció de la Direcció General de Promoció i EA destinada a actuacions d'EA. Això pot explicar la correlació existent entre la propietat dels centres privats i la seva inscripció al Cens.

Els projectes dels centres d'EA seleccionats es centren sobretot a elaborar noves activitats, nous materials, participar en projectes de cooperació i en campanyes ambientals.

\section{Sobre les activitats adreçades a batxillerat}

La informació i el contacte amb l'entitat per part dels docents arriba sobretot mitjançant els ens locals i comarcals. Els canals de difusió són dispersos i variats, però la majoria de centres tenen la seva pròpia web on es pot consultar la seva oferta.

La presentació de les activitats del centre d'EA al professorat es realitza com a preparació de l'activitat abans de la realització. En aproximadament la meitat de les activitats es pot trobar el dossier de l'alumnat a la pàgina web de l'entitat i només un $26 \%$ de les activitats tenen un dossier diferenciat per al professorat amb un assessorament didàctic. En general no hi ha seguiment després de l'activitat per part del centre d'EA i són pocs els que demanen una valoració per escrit de l'activitat.

L'oferta d'activitats és molt diversa, en durada, preu i tipologia. El temps destinat a realitzar l'activitat d'un taller com a mínim és d'una hora i si el taller inclou treball de camp pot arribar fins a les 4 hores. Les activitats de tot un dia van de les 5 a les 8 hores. Hi ha activitats que són gratuïtes, altres estan en part subvencionades i d'altres incorporen una sortida en barca que encareix el preu substancialment. Tallers, visites guiades, descoberta del medi i itinerari, són els tipus d'activitats més freqüents, però també xerrades, assessorament a treballs de recerca, sortides en barca, recursos audiovisuals i snorkel.

Les temàtiques més freqüents en les activitats seleccionades són les de biologia, les d'activitat humana i les d'impacte sobre el medi litoral-marí.

El treball que ha de realitzar l'alumnat és també molt variat. L'alumnat té una participació activa en l'activitat. La tasca que es realitza pot ser individual, o en grup. Majoritàriament realitza tasques per conèixer $\mathrm{i}$ emprar aparells $\mathrm{i}$ tècniques per al treball de camp i de laboratori per l'estudi del medi físic. Les activitats són guiades i en general es fa una presentació global de l'activitat i una explicació més teòrica sobre els conceptes que es treballaran; aquesta explicació s'acompanya amb recursos de 
suport (audiovisuals, làmines, maquetes, visita d'espais singulars o manipulació de material específic), després es realitza la part més pràctica de l'activitat i es conclou amb una interpretació de síntesi final.

Totes les activitats tenen un enfocament sobre el medi, basen majoritàriament la seva metodologia en l'observació i en menor freqüència en la identificació i en la descripció. El percentatge disminueix quan l'enfocament de les activitats és en el propi medi. Bàsicament les activitats en el medi són d'experimentació i de descoberta que es realitzen total o parcialment en el medi que s'està estudiant. Els itineraris, la recollida de dades o de mostres en la zona d'estudi són bons exemples d'aquesta metodologia que té una incidència menor. El tercer enfocament de les activitats per al medi és minoritari: es convida a la reflexió i a la responsabilitat com a primer pas per l'acció. Hi ha molt poques activitats que presentin els tres enfocaments: només un 17 per cent de les activitats tenen en major o menor grau els tres enfocaments.

L'alumnat de batxillerat visita poc els centres d'EA. La mitjana en percentatge és de 3'7\%, un valor molt baix que ens indica la poca quantitat d'alumnat de batxillerat que realitza sortides en aquests centres respecte d'altres nivells educatius. Aquesta dada contrasta amb la bona acceptació que aquestes activitats tenen per part de l'alumnat i del professorat.

\section{CONCLUSIONS}

$\mathrm{Hi}$ ha pocs centres d'educació ambiental amb oferta educativa relacionada amb el medi litoral que presentin activitats específiques per a l'alumnat de batxillerat. Tot i el nombre reduït de centres, el ventall d'aquestes activitats és força divers i apropen de forma variada l'alumnat al coneixement del medi natural. La distribució dels centres al llarg del litoral català i la diferent ubicació en el territori permeten diversificar les propostes educatives segons les possibilitats de l'entorn.

La diagnosi permet prendre consciència de l'estat actual i reflexionar sobre alguns aspectes que poden explicar les mancances d'oferta per a l'alumnat de batxillerat, incentivant noves línies d'investigació molt suggerents.

\section{BIBLIOGRAFIA}

CANADELL PRAT, À. (2007). Educació Sostenible: Criteris per a la introducció de la sostenibilitat en els processos educatius. Terrassa: Càtedra UNESCO de Sostenibilitat. UPC. [Data de con- sulta: 15 octubre 2007]

https://upcommons.upc.edu/e-

prints/bitstream/2117/628/1/educacio-

sostenible.pdf

GELI, A., JUNYENT, M. I d'altres (2006). L'ambientalització curricular en l'ensenyament obligatori: una proposta de definició, caracterització i estratègies. Monografies universitàries; 7. Barcelona: Generalitat de Catalunya. Departament de Medi Ambient i Habitatge. [Data de consulta: 15 octubre 2007]

http://mediambient.gencat.net/cat/ciutadans/edu ccio_ambiental/escoles_verdes/mu7_ambientaci o_curricular-def.pdf

GENERALITAT DE CATALUNYA (2003). ECEA: Estratègia Catalana d'Educació Ambiental: Una eina per a la comunicació i la participació. Document marc. Barcelona: Generalitat de Catalunya. [Data de consulta: 15 octubre 2007] http://mediambient.gencat.net/cat/ciutadans/edu ccio_ambiental/ecea/document_marc.jsp?Comp onentID=40830\&SourcePagelD=29226\#1

GENERALITAT DE CATALUNYA (1983). Itineraris $i$ Escoles de la Natura de Catalunya. Barcelona: Generalitat de Catalunya. Departament d'Ensenyament.

JUNYENT PUBILL, M. (2002). Educació ambiental: un enfocament metodològic en formació inicial del professorat d'Educació Primària. Girona: UdG. [Data de consulta: 15 octubre 2007] http://www.tesisenxarxa.net/TDX-0422104180430/index.html

LUCAS, A.M. (1979). Evironment and Evironment al Education: Conceptual Issures and Curricular Implications. Kew: Australian National Press and Publication.

LUNA, G. (1994). Recursos per a l'estudi del medi (actualització). Barcelona: Diputació de Barcelona.

MAYER, M. (1998). Educacion ambiental; de la acción a la investigación. Enseñanza de las ciencias, 16.

Mc KEOWN, (2002). Education for Sustainable Development Toolkit, Knoxville, TN: Center for Geography and Environmental Education, University of Tennessee.

NOVO, M. (1995). La educación Ambiental: Bases éticas, conceptuales y metodológicas. Madrid: Universitas.

PUJOL, J. (1991). Sobre la utilització de l'educació ambiental i d'alguns aspectes de la seva institucionalització. Barcelona: Societat Catalana d'Educació Ambiental.

STOKKING, K., VAN AERT, L., MEIJBERG, W., KASKENS, A. (2003). L'avaluació de l'educació ambiental. Barcelona: Graó. 
SUREDA, J. CALVO A. (1997). La xarxa Internet $i$ l'Educació Ambiental. Binissalem: Di7.

TERRADAS, Jaume (1983). Concepte $i$ objectius de l'educació ambiental. Barcelona: Diputació de Barcelona.

TILBURY, D. (1995). Environmental Education for Sustainability: defining the new focus of environmental education in the 1900s. Environmental Education Research,1.
Aquest article resumeix la diagnosi de l'oferta dins d'un treball més extens que podeu consultar a http://www.xtec.cat/ crodon1/. La base de dades es pot consultar a la secció suplement d'aquest mateix número de "Ciències".

Recerca realitzada gràcies a una llicència d'estudis retribuïda concedida pel Departament d'Educació de la Generalitat de Catalunya (DOGC núm. 4968 de 14.09.2007). 